\title{
Increased levels of clusterin (SGP-2) mRNA and protein accompany rat ventral prostate involution following finasteride treatment
}

\author{
S Astancolle, G Guidetti, C Pinna, A Corti and S Bettuzzi \\ Dipartimento di Scienze Biomediche, Università di Modena e Reggio Emilia, Via G. Campi 287, 41100 Modena, Italy \\ (Requests for offprints should be addressed to S Bettuzzi, Dipartimento di Scienze Biomediche, Università di Modena e Reggio Emilia, Via G. Campi 287, \\ 41100 Modena, Italy)
}

\begin{abstract}
Finasteride is a well-known inhibitor of the prostatic enzyme $5 \alpha$-reductase type 2 which prevents conversion of testosterone into $5 \alpha$-dihydrotestosterone, the active intraprostatic androgen, which causes prostate involution through a combination of cell atrophy and cell death. The drug is widely used to improve symptoms of benign prostatic hyperplasia in man. Clusterin, a glycoprotein which is generally up-regulated under conditions inducing cell atrophy or organ involution, is produced at a high level in the regressing rat ventral prostate following androgen ablation. According to several authors, clusterin does not respond to finasteride treatment, suggesting a different action of testosterone and $5 \alpha$-dihydrotestosterone. We show here that, under our conditions, finasteride was capable of inducing production of both clusterin mRNA and protein in the rat ventral prostate. In fact, by using
\end{abstract}

different and converging techniques, such as Northern hybridization, in situ hybridization histochemistry and immunohistochemistry, we were able to show a strong induction of the clusterin gene in the epithelial cell population of the gland. The response to finasteride, which was similar to that seen with castration, occurred with a delay of a few days. In situ and immunohistochemistry experiments indicated that both orchidectomy and finasteride administration resulted in increased transition of the epithelial cells from the columnar to the cuboidal (atrophic) shape, and this was accompanied by an increased intensity of the signal for clusterin. Thus, it appears that induction of clusterin is part of the molecular process leading to prostate involution caused by either orchidectomy or finasteride administration.

Journal of Endocrinology (2000) 167, 197-204

\section{Introduction}

Clusterin is a heterodimeric secreted glycoprotein whose mature glycosylated form in the rat ranges in size from 75 to $80 \mathrm{kDa}$. Identified independently by different laboratories in many tissues and body fluids it was given several different acronyms (sulfated glycoprotein 2 or SGP-2, TRPM-2, ApoJ, SP-40,40 etc.) (Kissinger et al. 1982, Blaschuk et al. 1983, Rosenberg \& Silkensen 1995) before it was realized that they were homologue forms of the same gene product. Hence the name clusterin has been proposed in accordance with an international consensus regarding terminology (Rosenberg \& Silkensen 1995). Depending on its localization within the body, clusterin appears involved in physiological processes as diverse as lipid transport, complement cascade regulation, membrane remodelling and programmed cell death (Rosenberg \& Silkensen 1995). In the rat ventral prostate, normal circulating levels of androgens maintain a very low clusterin concentration, due to the fact that, under these conditions, the clusterin gene is solely expressed in the cuboidal cells, a minor epithelial cell population undergoing apoptosis, but is not expressed in the columnar cells, which make up most of the prostatic epithelium and are active in the secretory function (Bettuzzi et al. 1992). Cuboidal cells are thought to derive from atrophy of columnar cells at the end of their life span (Lee et al. 1990). Upon androgen ablation, prostatic clusterin transiently accumulates at very high levels (Leger et al. 1987, Bettuzzi et al. 1989) in the gland as a consequence of clusterin gene derepression in the columnar cells (Bettuzzi et al. 1992). Since in the same cells, similarly to many other biological systems where clusterin is overexpressed (Rosenberg \& Silkensen 1995), apoptosis is concomitantly induced, the enhanced expression of this gene has been suggested to be a causative event of the apoptotic process. Recent reports, however, suggest that clusterin is up-regulated in death-surviving cells, rather than in cells doomed to die (French et al. 1994, Sensibar et al. 1995, Koch Brandt \& Morgans 1996). A very recent paper indicates that different forms of clusterin can be immunologically distinguished in apoptotic and death-surviving cells (Lakins et al. 1998).

It is well known that the major circulating androgen testosterone is rapidly converted to $5 \alpha$-dihydrotestosterone (DHT) within the prostate gland by membrane-bound NADPH-dependent 5 $\alpha$-reductase (Bruchovsky \& Wilson 
1968). Although DHT and testosterone share the same receptor, it is DHT, rather than testosterone, which is the active intraprostatic androgen (Bruchovsky \& Wilson 1968, Russell \& Wilson 1994). The two hormones appear to exert differential actions on rat prostate genes, as it has been shown by comparing the effects of $5 \alpha$-reductase (type 2) inhibition with those of castration (Avila et al. 1998). Indeed, administration of finasteride, a well-known competitive inhibitor of the enzyme that is widely used for the treatment of prostatic benign hyperplasia in humans (Russell \& Wilson 1994), dramatically reduces the level of DHT and causes testosterone to accumulate within the gland, while castration causes depletion of both steroids (Russell \& Wilson 1994). Existing data show that finasteride treatment results in a marked decrease in the weight of human and rat ventral prostate through a combination of atrophy and cell death (Rittmaster et al. 1995, 1996), similar to the effects of castration, but does not affect clusterin mRNA levels as castration does (Rittmaster et al. 1991, Fleshner \& Trachtenberg 1992, Shao et al. 1993, Russo et al. 1994, Shao et al. 1995). The only report, to our knowledge, showing induction by a steroidal $5 \alpha$-reductase inhibitor of clusterin expression in the rat ventral prostate was obtained with SK\&F105657, an uncompetitive inhibitor of $5 \alpha$-reductase (Lamb et al. 1992).

In order to understand more about the androgenic control of clusterin gene expression and, especially, whether testosterone and DHT exert a differential action on this process, we directly compared, in the ventral prostate of young adult rats, the effects of castration and finasteride treatment on the levels of clusterin mRNA and protein.

\section{Materials and Methods}

\section{Animal treatment}

Adult Sprague-Dawley rats (220-250 g body weight) were given finasteride $(40 \mathrm{mg} / \mathrm{kg} /$ day s.c.) in sesame oil. Castration was performed by the scrotal route under diethyl ether anaesthesia. The rats were cared for in accordance with guidelines published in Guidelines on the Handling and Training of Laboratory Animals (The Old School, Brewhouse Hill, Wheathampstead, Herts AL4 8AN, UK). At the end of the experimental period animals were killed by cervical dislocation.

\section{Tissue specimens}

After death, prostates were rapidly excised and cut into two almost identical parts. For each experimental condition, one-half of the gland from each animal was pooled. The pooled tissues were then used for total RNA extraction. The number of animals used for each experimental condition ranged from 4 (controls and 2 day treated) to 10
( 8 day treated). The remaining portions of each prostate were kept separate and quickly frozen (covered with dry ice powder) on a flat glass surface at $-80^{\circ} \mathrm{C}$, in order to generate a suitable cutting surface for the cryostat. Starting from the flat surface, $14 \mu \mathrm{m}$ sections were cut. Alternate sections were used for in situ hybridization or immunohistochemistry experiments in contiguous sections, for direct comparison of transcript and protein cellular distribution.

\section{Northern hybridization analysis}

Total RNA was extracted using RNAFast from Molecular Systems (San Diego, CA, USA). Ten microgram aliquots were then electrophoresed on a $1 \%$ agarose-formaldehyde gel and blotted onto Hybond-N nylon membranes from Amersham Pharmacia Biotech (UK). All blots were then hybridized to the specific rat clusterin $1.5 \mathrm{~kb}$ full-length cDNA probe (Bettuzzi et al. 1989) and subsequently reprobed with the $1.2 \mathrm{~kb}$ full-length GAPDH cDNA probe, as previously described (Bettuzzi et al. 1994). Probes were labelled by random priming $\left[{ }^{32} \mathrm{P}\right] \mathrm{dCTP}$ incorporation (Bettuzzi et al. 1994). SGP-2 mRNA size was about $1.8 \mathrm{~kb}$, while GAPDH mRNA size resulted about $1.3 \mathrm{~kb}$. Northern hybridization analysis was carried out four times, using four separate pools of rat tissue. Quantification of the autoradiograms was obtained by densitometric scanning using an LKB Ultrascan XL densitometer.

\section{In situ hybridization}

The in situ hybridization experiments were performed using a ${ }^{35}$ S-labelled oligodeoxyribonucleotide probe specific for rat clusterin mRNA as previously described (Marinelli et al. 1994). For every experimental condition, three alternate sections from three different rat prostates were examined and the results were compared with those obtained by immunohistochemistry experiments performed in the three corresponding contiguous sections. To exclude non-specific hybridization other than clusterin mRNA, the experimental conditions used for in situ experiments included the use of sense controls, different anti-sense oligonucleotides targeting different regions of the same mRNA and oligonucleotides of the same length and GC content as clusterin probe but containing unrelated sequences (Marinelli et al. 1994). Digital black and white images of the autoradiograms of whole gland cross-sections were acquired directly by means of a CCD camera, while digital high-magnification photomicrographs, showing the cellular distribution of the ${ }^{35}$ S-labelled oligonucleotide probe for clusterin mRNA, were acquired by means of a CCD camera through the microscope, after treatment of the above sections with photographic emulsion. 


\section{Immunohistochemistry}

The entire experimental procedure was performed at room temperature. The monoclonal anti-rat clusterin antibody was from UPSTATE Biotechnology (Lake Placid, NY, USA). Prostate sections were post-fixed with $4 \%$ paraformaldehyde in phosphate-buffered saline (PBS) ( $\mathrm{pH} 7 \cdot 4$ ) for $30 \mathrm{~min}$, and then washed for $5 \mathrm{~min}$ in PBS. Sections were incubated for $1 \mathrm{~h}$ with the primary antibody diluted 1:50 in PBS containing 0.3\% Triton X-100, extensively rinsed in PBS, and exposed for $1 \mathrm{~h}$ to the secondary antibody anti-mouse Ig biotinylated species-specific whole antibody (Amersham Pharmacia Biotech, UK), diluted 1: 200 in PBS. Sections were extensively rinsed again in PBS, and incubated for $45 \mathrm{~min}$ with the streptavidinbiotinylated horseradish peroxidase complex (Amersham Pharmacia Biotech, UK), diluted 1:300 in PBS. After rinsing several times in PBS, the sections were incubated for $5 \mathrm{~min}$ in the presence of a saturating concentration of $3,3^{\prime}$-diaminobenzidine (DAB) and $\mathrm{H}_{2} \mathrm{O}_{2}$ using the Sigma Fast $^{\mathrm{TM}} \mathrm{DAB}$ peroxidase substrate tablet set (SIGMA, St Louis, MO, USA), according to the manufacturer's instructions. The reaction was blocked washing the sections in distilled water for $5 \mathrm{~min}$. All the sections obtained from controls and treated animals were processed in parallel under identical reaction conditions. For every experimental condition, three alternate sections from three different rat prostates were examined and the results were compared with those obtained by in situ hybridization experiments performed in the three corresponding contiguous sections. Experiments performed using polyclonal anti-rat clusterin antibodies from the same commercial source gave the same pattern of specific distribution, while no specific signal was detected when using monoclonal anti-human clusterin antibodies from the same source. Negative controls, made by excluding mono- or polyclonal anti-rat antibodies from the reaction, showed no specific staining. Counterstaining was performed with haematoxylin, and coverslips were mounted with Eukitt (O Kindler GmbH \& Co., Germany). Digital highmagnification colour images were acquired by means of a CCD camera through the microscope.

\section{Results}

Daily injections of finasteride in adult rats caused a marked decrease of ventral prostate weight that began on day 2 after starting the treatment, was $50 \%$ of the control on day 4 , and remained at that level up to day 8 (not shown). Similar data were reported by many authors (Rittmaster et al. 1991, Fleshner \& Trachtenberg 1992, Shao et al. 1993, 1995, Russo et al. 1994). Castration also resulted in prostate involution, with a progressive and more pronounced decrease of the ventral prostate weight, which was reduced by $85 \% 8$ days after the operation (not shown). Titration of clusterin mRNA by Northern blot hybridization (Fig. 1) showed enhancements in the accumulation of this transcript 2 and 4 days after initiation of the finasteride treatment, followed by a strong increase at day 6 (a mean value of more than 10-fold out of four separate experiments carried out using four separate pools of rat tissues) and especially at day 8 (a mean value of more than 25-fold). The GAPDH mRNA hybridization signal obtained after reprobing the same blot is also shown for comparison (Fig. 1). A decrease in the accumulation of GAPDH mRNA is evident in finasteride-treated rats.

In castrated animals clusterin mRNA started to accumulate at very high levels 2 days after surgery, as previously shown (Bettuzzi et al. 1989), and continued to increase up to 6 days, the mean increase being 20-fold, a value very close to that seen on day 8 in finasteride-treated rats. Eight days after castration the level of clusterin transcript was markedly reduced, in accordance with the known transient effect of testosterone depletion on clusterin gene expression. The minor differences in the kinetics of clusterin induction in castrated rats, with respect to our previous results (Bettuzzi et al. 1989) could be due to the different size/age of the animals (i.e. 90-120 g compared with 220-250 g for the data reported here). It is well known that the response to androgen manipulation is age related. Four-month-old (fully adult) animals were chosen to study the effect of finasteride in an animal model that more closely resembles the clinical condition in which the drug is routinely administered: for the management of prostatic benign hyperplasia, finasteride is usually given to patients of $45-75$ years old. A modest decrease in the accumulation of GAPDH mRNA is also evident in castrated rats. The diminution in GAPDH mRNA levels in both finasteride-treated and castrated animals could be due to the decrease in the epithelial cells/stroma ratio that is known to occur during prostate involution. As previously shown (Bettuzzi et al. 1989), in two day castrated rats given DHT, clusterin mRNA levels were progressively reduced, returning to basal levels within 5 days of DHT treatment, when the regrowth of the involuted prostate was complete (data not shown).

Induction of clusterin expression in the rat ventral prostate by finasteride treatment was fully confirmed by in situ hybridization experiments with a ${ }^{35}$ S-labelled oligodeoxynucleotide probe specific for clusterin mRNA (Marinelli et al. 1994). Figure 2 shows an example of the autoradiograms and photomicrographs obtained upon hybridization of ventral prostate sections from intact, 4 day castrated and finasteride-injected rats. The increased accumulation of clusterin mRNA in 8 day finasteridetreated rats is similar to 4 day castrated animals, although less dramatic, and it accompanies the transition of the prostatic epithelium from the columnar to the cuboidal shape that occurs both with castration and finasteride administration. The preferential expression of clusterin in the cuboidal cells of the prostatic epithelium is evident also 

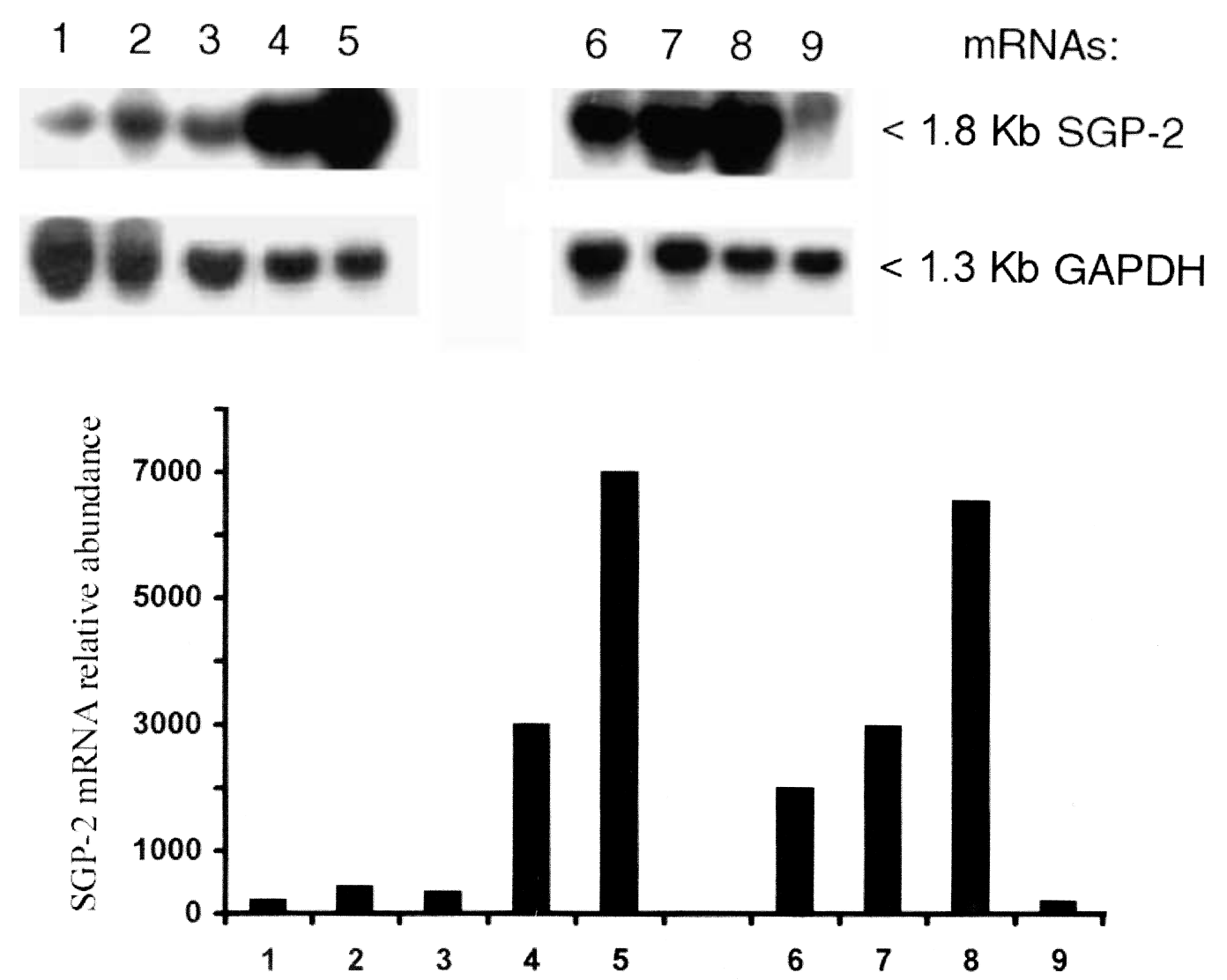

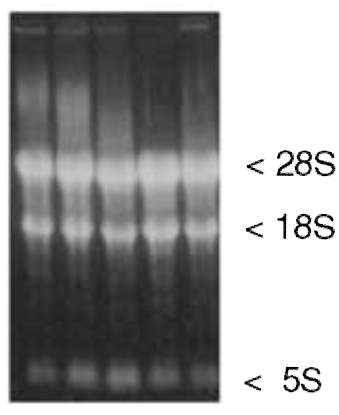

12345

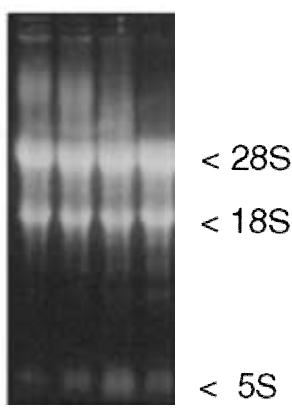

6788

Figure 1 Representative Northern hybridization experiments of clusterin (SGP-2) mRNA performed on total RNA extracted from pools of ventral prostates obtained from control, finasteride-injected or castrated rats. Lane 1: intact animals; lanes 2-5: 2, 4, 6 and 8 days of finasteride treatment, respectively; lanes 6-9: 2, 4, 6 and 8 day castrates, respectively. The same control was used for both castration and finasteride treatment, because previous experiments showed no significant differences in the levels of clusterin between intact, sham-operated and sesame oil-injected rats for the time intervals studied. The specific clusterin mRNA radioactive signals were quantified by densitometric scanning of the autoradiograms and reported in the histogram. The GAPDH mRNA hybridization signal is also shown for comparison. The values for clusterin expression reported in the histogram have not been adjusted for the variations in GAPDH and correspond to the intensity of the hybridization signals shown. Y-axis: relative optical density. Ten micrograms of total RNA was loaded on each lane; the ethidium bromide staining of the RNA specimens, separated on agarose gel, is also shown to demonstrate equal loading of the gels. The data shown are representative of four determinations obtained in separate sets of experiments. 

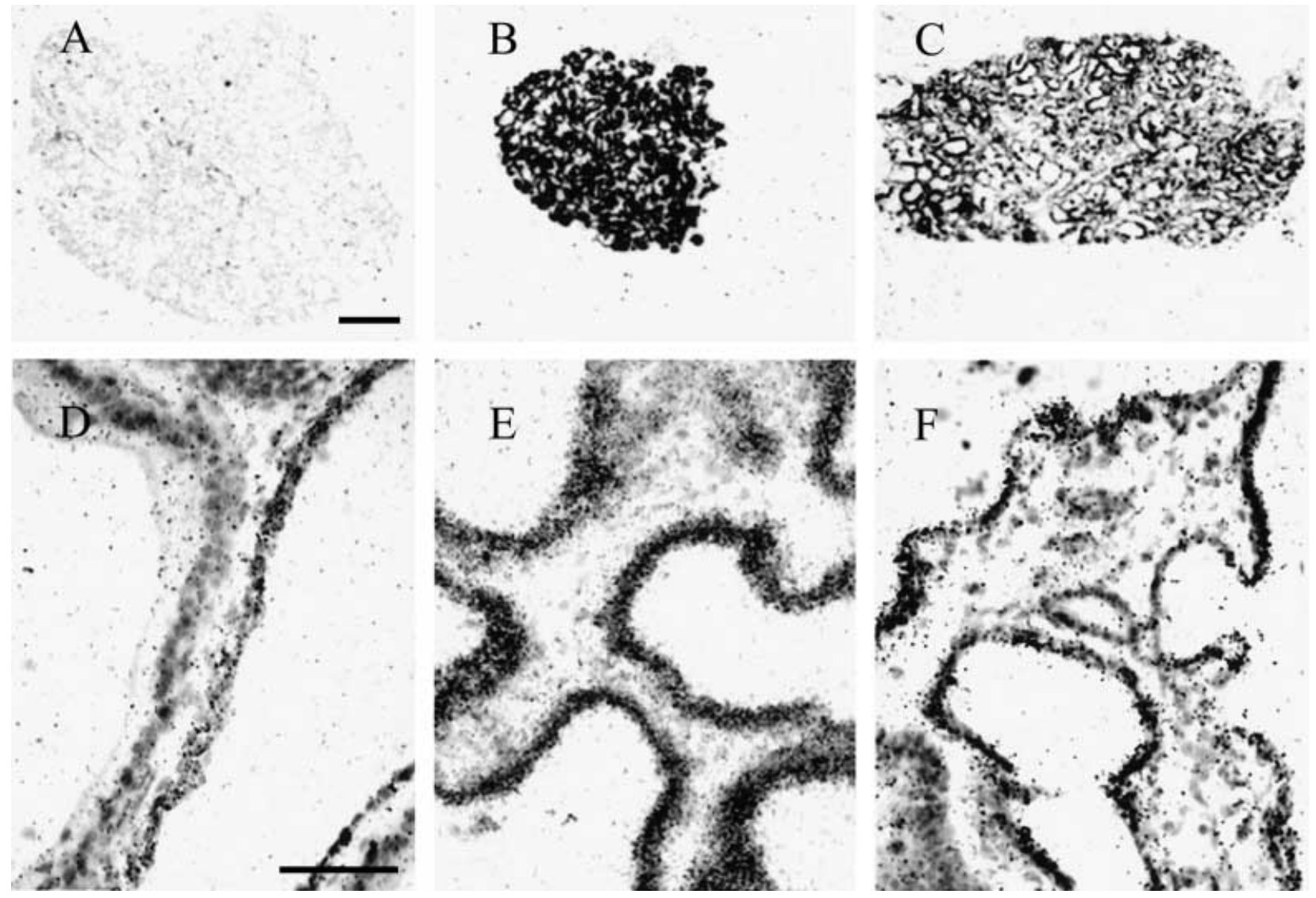

Figure 2 In situ hybridization histochemistry of clusterin (SGP-2) mRNA on ventral prostate from intact (A and D), 4 day castrated ( $\mathrm{B}$ and $\mathrm{E})$ or 8 day finasteride-injected rats $(\mathrm{C}$ and $\mathrm{F})$. A-C: representative autoradiograms of cross-sections $(14 \mu \mathrm{m})$ of the whole gland (calibration bar $=1 \mathrm{~mm}$ ). D-F: photomicrographs showing the cellular distribution of the ${ }^{35}$ S-labelled oligonucleotide probe for clusterin mRNA in the above sections after treatment with photographic emulsion and counterstaining with haematoxylin-eosin. Notice that the hybridization signal in D is consistent with basal expression of clusterin in cuboidal cells of the prostate ducts from intact animals. Here a field was chosen for both columnar (left) and cuboidal (right) cells in order to compare directly the level of clusterin expression in these two cell types. The preferential expression of clusterin in the latter is evident, as well as the fact that cuboidal atrophic cells are largely present in finasteride-treated prostate specimens and show very high levels of clusterin mRNA (F) (calibration bar=50 $\mu \mathrm{m})$.

in the gland of control animals (Fig. 2D), which may explain the low level of clusterin expression in control rats, due to the small size of this cell population (Bettuzzi et al. 1992).

Changes in clusterin gene product accumulation, as a consequence of changes in the levels of clusterin transcript under the effect of finasteride or orchidectomy, were also detected by immunohistochemistry assay using monoclonal anti-rat clusterin antibody (Fig. 3). As previously shown (Bettuzzi et al. 1992, 1994, Marinelli et al. 1994), the signal for clusterin protein, although very low, is present in the ventral prostate of intact rats (Fig. 3A). In fact, in normal prostate, clusterin-specific staining is present only in the atrophic cells, and not in tall columnar cells (compare top left with bottom right of Fig. 3A, where the transition between the tall columnar epithelial cells and the cuboidal atrophic ones is shown).
After starting finasteride treatment, the clusterin signal becomes increasingly evident; on day 6 (Fig. 3C) and day 8 (Fig. 3D), a staining intensity similar to that seen in 4 day castrated animals (Fig. 3B) was reached. Although caution should be exercised when making comparisons because in situ and immunohistochemistry evaluations are only semi-quantitative, a good correlation between the intensity of clusterin mRNA (compare Fig. $2 \mathrm{E}$ and F) and protein (compare Fig. 3B and D) signals is evident in 4 day castrated and 8 day finasteride-treated specimens. In both finasteride-treated and castrated rats clusterin localizes to the cytoplasmic compartment of epithelial cells. Noticeably, most of the epithelial cells expressing clusterin shift from the columnar to the cuboidal shape between 2 and 4 days after castration (not shown), while this morphological change appears to occur to a significant extent only between 6 and 8 days after finasteride administration 

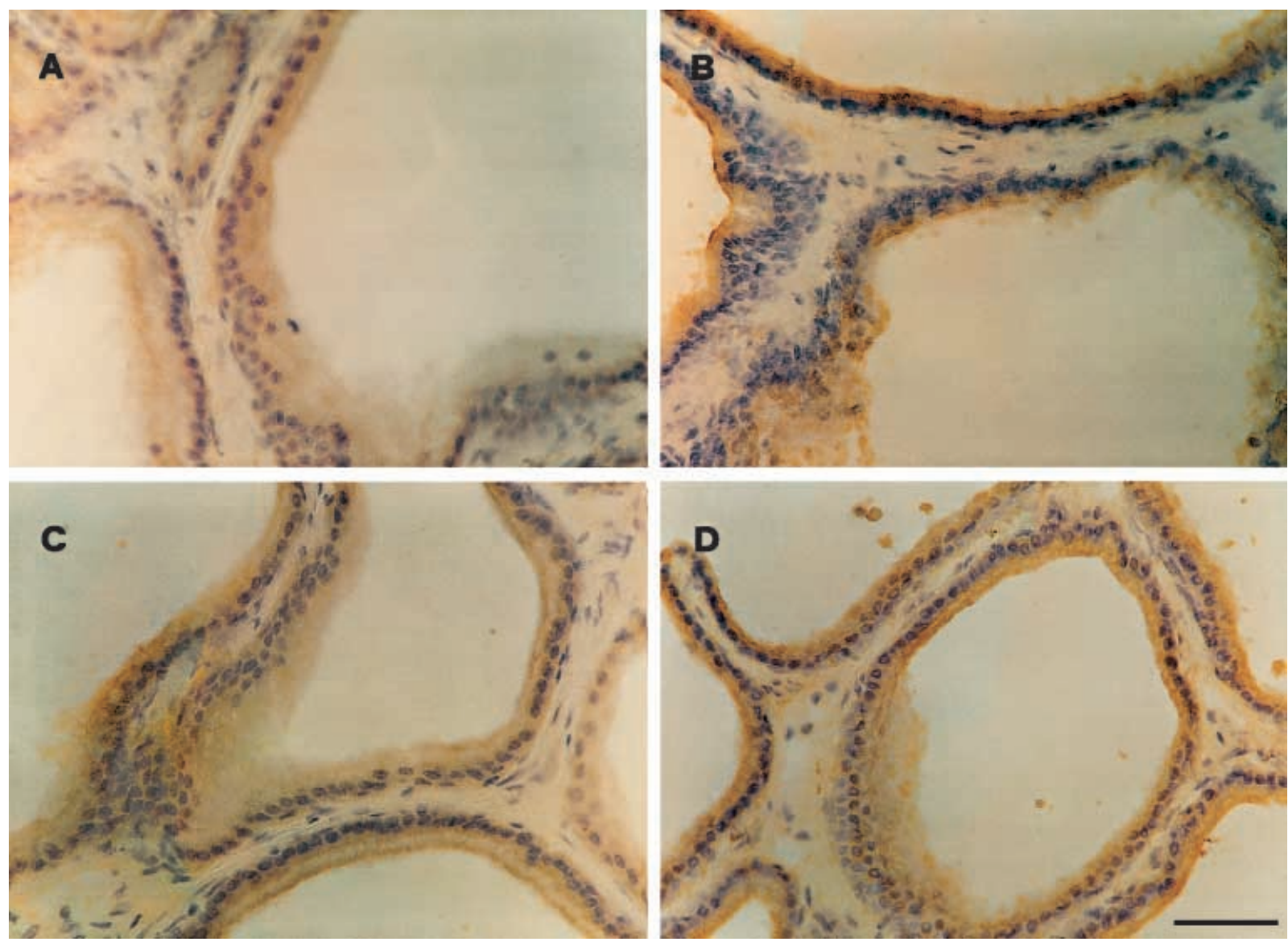

Figure 3 Immunohistochemistry detection of clusterin (SGP-2) in rat ventral prostate. A: intact; B: 4 day castrated; C: 6 day finasteride treated; D: 8 day finasteride treated. Representative fields obtained from cross-sections $(14 \mu \mathrm{m})$ of whole prostate glands stained with a monoclonal anti-rat clusterin antibody. Counterstaining with haematoxylin (calibration bar $=50 \mu \mathrm{m}$ ). Clusterin expression in 8 day finasteride-treated (D) is similar to that of 4 day castrated (B) glands and is confined to the cytoplasm of epithelial cells. The clusterin signal in intact rat prostate is generally very low and most of the sections show very little staining. In A, a field was chosen to show the transition between the tall columnar epithelial cells and the cuboidal atrophic ones (in the middle of the field, from bottom to top, respectively). Clusterin expression is detectable only in the atrophic cells and not in columnar cells (compare middle-top, where cuboidal atrophic epithelial cells are abundant, with bottom right, where most of the epithelial cells are columnar). Cuboidal atrophic cells are also largely present in prostate specimens from finasteride-treated and castrated rats and show the highest level of expression of the protein (B-D).

(Fig. 3C and D). Thus clusterin accumulation seems to be strictly related to this kind of cell involution.

\section{Discussion}

Normal androgen circulating levels prevent clusterin expression in the great majority of the rat prostate cells, and castration-induced androgen depletion markedly enhances clusterin expression in the same cells. It has long been debated whether administration of the $5 \alpha$-reductase type 2 inhibitor finasteride induces the expression of clusterin gene similarly to orchidectomy. Several papers have reported that the drug does not affect the levels of clusterin mRNA in the rat prostate (Rittmaster et al. 1991, Fleshner \& Trachtenberg 1992, Shao et al. 1993, 1995, Russo et al. 1994), although it causes a decrease in weight of the gland that, similarly to castration, results from a combination of cell atrophy and cell death (Rittmaster et al. 1995, 1996). This discrepancy may depend on the different sensitivities of the methods followed, as discussed also by Rittmaster et al. (1995). We show here that in adult rats, both clusterin mRNA and protein respond to finasteride administration with a time course pattern similar to that following castration, the main difference being a delay in the response of clusterin accumulation. In fact, a strong increase in the abundance of the clusterin transcript is seen as early as 2 days after castration, but a 
similar response to finasteride is only seen 6 days after initiation of the treatment.

$5 \alpha$-reductase type 2 inhibition is followed by a marked increase of intraprostatic testosterone (Rittmaster et al. 1995); since the latter binds the same receptor as DHT, although with a lower affinity, it could conceivably replace DHT in maintaining the repressed clusterin gene. It remains to be explained, however, which phenomenon causes the levels of clusterin to rise so dramatically at 6 and 8 days of finasteride treatment. A decrease in the levels of testosterone at the latter times is not the answer, since it has been shown that, after the changes of DHT and testosterone levels occurring within the first 4 days of finasteride treatment (same dose used here), both androgens remained remarkably constant up to 21 days (Rittmaster et al. 1995). A tentative explanation may be found in the possible down-regulatory effect that might be exerted by high levels of intraprostatic testosterone on the androgen receptor.

It is apparent from both the in situ and immunohistochemistry data (Figs 2, 3 and Bettuzzi et al. 1992) that cells of the prostatic epithelium which survive the burst of apoptosis occurring shortly after androgen depletion, are of cuboidal type; following finasteride injection, the transition from columnar cells (functionally active) into cuboidal, atrophic cells occurs with a delay with respect to castration, that appears to mirror the delay shown by clusterin overexpression. This confirms the strict association of clusterin expression with prostatic epithelial cell involution. The fact that the clusterin gene product appeared in columnar cells and was abundantly expressed in the cuboidal ones suggests that this gene plays a role in the cells that survive death, and this is similar to what we have shown in the gland of the ageing rats, where the age-dependent increased accumulation of clusterin transcript (Bettuzzi et al. 1994) was found to be due to a parallel increase in the number of atrophic, clusterinexpressing cuboidal cells, at the expense of the columnar ones, that exhibited no or little clusterin expression (Bettuzzi et al. 1992, Marinelli et al. 1994). Thus, it appears that castration and $5 \alpha$-reductase type 2 inhibition lead to prostate involution by affecting the same mechanism(s), although with different timing and intensity.

\section{Acknowledgements}

This research was developed in the framework of the collaborative network BIOMED 2. This work was partially supported by: Associazione Italiana 'Spes Nova' per lo Studio dei Meccanismi Biomolecolari della Malattia Neoplastica, Bologna, Italy; MURST (Roma): Programma di Ricerca Scientifica di Rilevante Interesse Nazionale - 'Studio di alcuni Parametri Biochimici del Carcinoma Prostatico'.

\section{References}

Avila DM, Fuqua SA, George FW \& McPhaul MJ 1998 Identification of genes expressed in the rat prostate that are modulated differently by castration and finasteride treatment. Journal of Endocrinology 159 403-411.

Bettuzzi S, Hiipakka RA, Gilna P \& Liao ST 1989 Identification of an androgen-repressed mRNA in rat ventral prostate as coding for sulphated glycoprotein 2 by cDNA cloning and sequence analysis. Biochemical Journal 257 293-296.

Bettuzzi S, Zoli M, Ferraguti F, Ingletti MC, Agnati LF \& Corti A 1992 Regional and cellular distribution within the rat prostate of two mRNA species undergoing opposite regulation by androgens. Journal of Endocrinology 132 361-367.

Bettuzzi S, Strocchi P, Marinelli M, Astancolle S, Davalli P \& Corti A 1994 Gene relaxation and aging: changes in the abundance of rat ventral prostate SGP-2 (clusterin) and ornithine decarboxylase mRNAs. FEBS Letters 348 255-258.

Blaschuk O, Burdzy K \& Fritz IB 1983 Purification and characterization of a cell-aggregating factor (clusterin), the major glycoprotein in ram rete testis fluid. Journal of Biological Chemistry 258 7714-7720.

Bruchovsky N \& Wilson JD 1968 The conversion of testosterone to 5-alpha-androstan-17-beta-ol-3-one by rat prostate in vivo and in vitro. Journal of Biological Chemistry 243 2012-2021.

Fleshner NE \& Trachtenberg J 1992 Sequential androgen blockade: a biological study in the inhibition of prostatic growth. Journal of Urology 148 1928-1931.

French LE, Wohlwend A, Sappino AP, Tschopp J \& Schifferli JA 1994 Human clusterin gene expression is confined to surviving cells during in vitro programmed cell death. Journal of Clinical Investigation 93 877-884.

Kissinger C, Skinner MK \& Griswold MD 1982 Analysis of Sertoli cell-secreted proteins by two-dimensional gel electrophoresis. Biology of Reproduction 27 233-240.

Koch Brandt C \& Morgans C 1996 Clusterin: a role in cell survival in the face of apoptosis? Progress in Molecular and Subcellular Biology 16 130-149.

Lakins J, Bennett SA, Chen JH, Arnold JM, Morrissey C, Wong P, O'Sullivan J \& Tenniswood M 1998 Clusterin biogenesis is altered during apoptosis in the regressing rat ventral prostate. Journal of Biological Chemistry 273 27887-27895.

Lamb JC, English H, Levandoski PL, Rhodes GR, Johnson RK \& Isaacs JT 1992 Prostatic involution in rats induced by a novel 5 alpha-reductase inhibitor, SK\&F 105657: role for testosterone in the androgenic response. Endocrinology 130 685-694.

Lee C, Sensibar JA, Dudek SM, Hiipakka RA \& Liao ST 1990 Prostatic ductal system in rats: regional variation in morphological and functional activities. Biology of Reproduction 43 1079-1086.

Leger JG, Montpetit ML \& Tenniswood MP 1987 Characterization and cloning of androgen-repressed mRNAs from rat ventral prostate. Biochemical and Biophysical Research Communications 147 196-203.

Marinelli M, Quaglino D, Bettuzzi S, Strocchi P, Davalli P \& Corti A 1994 Increased levels of clusterin mRNA in the ventral prostate of the aging rat are associated to increases in cuboidal (atrophic) cell population and not to changes in apoptotic activity. Biochemistry and Cell Biology 72 515-521.

Rittmaster RS, Magor KE, Manning AP, Norman RW \& Lazier CB 1991 Differential effect of 5 alpha-reductase inhibition and castration on androgen-regulated gene expression in rat prostate. Molecular Endocrinology 5 1023-1029.

Rittmaster RS, Manning AP, Wright AS, Thomas LN, Whitefield S, Norman RW, Lazier CB \& Rowden G 1995 Evidence for atrophy and apoptosis in the ventral prostate of rats given the 5 alpha-reductase inhibitor finasteride. Endocrinology 136 741-748.

Rittmaster RS, Norman RW, Thomas LN \& Rowden G 1996 Evidence for atrophy and apoptosis in the prostates of men given 
finasteride. Journal of Clinical Endocrinology and Metabolism $\mathbf{8 1}$ 814-819.

Rosenberg ME \& Silkensen J 1995 Clusterin: physiologic and pathophysiologic considerations. International Journal of Biochemistry and Cell Biology 27 633-645.

Russell DW \& Wilson JD 1994 Steroid 5 alpha-reductase: two genes/two enzymes. Annual Review of Biochemistry 63 25-61.

Russo P, Warner JA, Huryk R, Perez G \& Heston WD 1994 TRPM-2 gene expression in normal rat ventral prostate following castration and exposure to diethylstilbestrol, flutamide, MK-906 (finasteride), and coumarin. The Prostate 24 237-243.

Sensibar JA, Sutkowski DM, Raffo A, Buttyan R, Griswold MD, Sylvester SR, Kozlowski JM \& Lee C 1995 Prevention of cell death induced by tumor necrosis factor alpha in LNCaP cells by overexpression of sulfated glycoprotein-2 (clusterin). Cancer Research $552431-2437$.

Shao TC, Kong A, Marafelia P \& Cunningham GR 1993 Effects of finasteride on the rat ventral prostate. Journal of Andrology 14 79-86.

Shao TC, Marcelli M, Kong A \& Cunningham GR 1995 Antiandrogen effects of the aromatase inhibitor, atamestane. Journal of Andrology 16 100-107.

Received 8 December 1999

Revised manuscript received 14 June 2000 Accepted 28 June 2000 